\title{
A implementação do Programa Bolsa Família sob a perspectiva da condicionalidade educacional: uma análise a partir dos agentes públicos de base
}

Breynner Ricardo de Oliveira

Universidade Federal de Ouro Preto (UFOP)

Este artigo analisa a implementação do Programa Bolsa Família na cidade de Belo Horizonte, a partir dos agentes de base (street-level bureaucrats), sob a perspectiva da condicionalidade educacional. O programa transfere uma bolsa para famílias em situação de pobreza, vinculando o pagamento ao cumprimento de corresponsabilidades nas áreas da educação e saúde. Lipsky (1980) é uma referência nesse campo, porque, ao analisar esse processo a partir da perspectiva dos atores que estão na ponta, assume que tais agentes exercem influência sobre essas políticas, alterando seu curso de ação. Nessa cidade, os profissionais da educação e da assistência são os que correspondem à caracterização do autor. As 31 entrevistas realizadas indicam que há tipos diferentes de interação, explicados pelas distintas percepções, valores e interpretações que esses atores constroem quando desempenham suas funções, estimulando o fortalecimento de redes de cooperação. A pesquisa revela que essa condicionalidade mobiliza os agentes de base, mesmo quando a intersetorialidade ainda é um problema institucional.

Palavras-chave: políticas públicas, agente público, discricionariedade, implementação, política social

Artigo recebido em maio de 2014. Versão final em setembro de 2014. 
La implementación del Programa Bolsa Familia bajo la perspectiva de la condicionalidad educacional: un análisis a partir de los agentes públicos de base

Este artículo examina la implementación del Programa Bolsa Familia en la ciudad de Belo Horizonte, a partir de los agentes básicos ( burócratas a nivel de calle), desde la perspectiva de la condicionalidad educativa. El programa transfiere una beca a las familias en situación de pobreza con la vinculación del pago al cumplimiento de corresponsabilidades en las áreas de educación y salud. Lipsky (1980) es una referencia en este campo, ya que, en el análisis de este proceso desde la perspectiva de los actores que están en el borde, se supone que estos agentes ejercen influencia sobre estas políticas, cambiando su curso de acción. En esta ciudad, los maestros y trabajadores sociales son los correspondientes a la caracterización del autor. Las 31 entrevistas indican que hay difereA implementantes tipos de interacción, explicado por las diferentes percepciones, valores e interpretaciones que estos actores construyen cuando realizan sus funciones, fomentando el fortalecimiento de las redes de cooperación. La investigación revela que esta condicionalidad moviliza los agentes.

Palavras clave: políticas públicas, funcionario público, discricionariedad, implementación, política social

The implementation of the Bolsa Familia Program and the educational conditionality: the role played by street-level bureaucrats

This article examines the implementation of the Bolsa Familia Program in the city of Belo Horizonte (Brazil) considering the role played by street-level bureaucrats regarding the program's educational conditionality. The program grants a benefit to poor families in compliance with co-responsibilities in education and health. Lipsky (1980) is a reference in this field because he analyses this process from the perspective of actors who are on the edge of policies, assuming that these agents exert influence on these policies by changing their course of action. In this city, school and social workers are the ones who correspond to Lipsky's characterization. The interviews indicate that there are different types of interaction, explained by different perceptions, values and interpretations that these actors construct when they perform their duties, encouraging the strengthening of cooperation networks. The research reveals that the program's conditionality mobilizes street-level agents, even when intersectoral support is still an institutional problem.

Key words: public policy, civil servant, discretion, implementation, social policy 


\section{Introdução}

O Programa Bolsa Família (PBF) foi criado pelo Governo Lula em 2003 com a missão de unificar os programas nacionais de transferência de renda existentes (Bolsa Escola Federal, Bolsa Alimentação, Auxílio Gás, Cartão Alimentação e Programa de Erradicação do Trabalho Infantil). Ao direcionar recursos para a população em situação de pobreza/pobreza extrema, o PBF incorpora, na sua arquitetura, um conjunto de condições que devem ser satisfeitas pelas famílias beneficiadas, vinculando-as ao programa.

Em relação à condicionalidade educacional, os programas de transferência de renda com contrapartidas (PTRC) articulam-se com várias outras políticas, utilizando o aluno bolsista e a escola como elementos condicionantes do recebimento do recurso, ampliando seu caráter institucional no processo de implementação de políticas públicas. A escola não é, portanto, uma instância comprometida apenas e tão somente com sua dimensão curricular, pedagógica e formativa. De acordo com Algebaile (2009), há uma série de atribuições conferidas a ela que marcam sua posição como materializadora da ação estatal por meio da burocracia governamental, sobretudo em relação às políticas sociais historicamente desenhadas para os mais pobres ou desfavorecidos.

Do ponto de vista dos agentes públicos que integram esses (e outros) espaços e que estão envolvidos no processo de implementação de PTRC junto aos cidadãos (professores, profissionais da educação e da saúde e assistentes sociais são alguns dos atores que atuam nessa cadeia), pode-se afirmar que esses sujeitos desempenham uma grande variedade de funções, nem sempre diretamente ligadas às suas atividades "oficiais". Segundo Lipsky (1980), esses agentes são, portanto, atores que detém algum poder discricionário e, por isso, podem promover modificações no curso das ações e/ou resultados dos programas.

De acordo com esse autor, a população afetada pela política e os agentes públicos de base em contato com ela (os chamados street-level bureaucrats ou burocratas no nível da rua) poderiam e deveriam influenciar de forma mais intensa o processo de planejamento de políticas públicas. Para Winter (1993; 2003), como esses profissionais estão "na ponta", o exercício cotidiano de suas funções molda suas estratégias de ação, incrementando os ganhos de eficácia e eficiência dos programas.

Em relação ao PBF, a condicionalidade educacional vincula, de alguma forma, todos os atores que integram a estrutura organizacional dessas unidades, além de aproximá-los de outros agentes públicos externos a essa estrutura, que acabam também envolvidos e envolvendo aqueles primeiros. No momento em que se 
depende desses agentes para que as políticas efetivamente aconteçam, entender como os papéis são desempenhados é crucial para que se compreenda o itinerário percorrido pelas políticas dentro e fora daqueles espaços.

Considerando essa perspectiva analítica como referência, a escola emerge como instituição permeada por questões organizacionais informais ou ocultas, muitas delas desvinculadas do núcleo pedagógico propriamente dito. Segundo Shiroma (2007), a escola pública é, também, um dos vários elos da ação estatal, estando sujeita aos diferentes objetivos estratégicos de distintos governos. Nessa perspectiva, a escola integra a estrutura burocrática do Estado, o que faz com que, em maior ou menor grau, sujeite-se às diretrizes definidas por esses governos. Tendo isso em vista, pretende-se, neste artigo, analisar o processo de implementação do PBF em Belo Horizonte sob a perspectiva da condicionalidade educacional.

\section{A implementação de políticas públicas e os agentes de base}

De acordo com Hill (1997), duas concepções de análise surgidas no campo das políticas públicas ajudam a compreender como o processo de implementação acontece: os modelos top-down e bottom-up. A pergunta feita por esses modelos está relacionada com o nível de atuação discricionária que os agentes implementadores possuem. Cada modelo adota um tipo diferente de visão sobre o assunto, apostando que o sucesso da implementação é influenciado por essa variável em uma das direções e pela conexão existente entre a direção escolhida e o tipo de política e ambiente onde ela é inserida.

Segundo aquele autor, o modelo top-down (de cima para baixo) parte do pressuposto que as ações dos agentes públicos são direcionadas ao cumprimento das metas traçadas na fase de formulação, que antecede a implementação. Para essa vertente, os objetivos estabelecidos na fase de formulação devem ser seguidos rigorosamente no momento seguinte, e essa fase deve reunir todos os meios necessários para que o plano traçado seja cumprido.

Há, assim, uma nítida separação entre as fases de formulação e de implementação de políticas públicas. Assume-se que a política opera em um fluxo hierárquico, de cima pra baixo. As políticas são formuladas pelos superiores e a administração apenas executa o que foi pensado nas etapas anteriores. A função dos agentes públicos se limita a apenas cumprir as metas estabelecidas no processo de formulação. Nesse modelo, a discricionariedade dos burocratas implementadores não é encorajada e as regras devem ser claras a fim de impedir qualquer decisão individual dos agentes.

O outro modelo - bottom-up (de baixo para cima) - critica a visão anterior centrada no processo hierarquizado. Para Hill (1997), a implementação é parte de 
um processo contínuo que se desenvolve e se modifica em cada fase. Esse modelo propõe que a implementação deve ser um jogo que possibilite o aprendizado e a criação de políticas, que devem ser compreendidas como um processo de realização de experimentos que poderão desdobrar-se em novas políticas, não sendo possível exercer um controle perfeito ao longo de sua execução.

Lipsky (1980), um dos principais pesquisadores a partir dessa perspectiva, afirma que certas situações não previstas anteriormente só podem ser resolvidas no momento em que ocorrem e essa solução se dá com a decisão discricionária tomada pelos agentes. Como são os próprios agentes que se relacionam diretamente com os cidadãos e que possuem o verdadeiro conhecimento sobre a situação, não se pode exigir deles a tomada de uma decisão que seja baseada numa solução definida abstratamente. De acordo com Wilson (1989) e Moody \& Musheno (2003), os agentes, ao tomarem uma decisão, sofrem vários tipos de influências, podendo criar novos meios de implementação da política ou, até mesmo, novos objetivos para o programa. Por isso, pode-se dizer que a política muda à medida que é executada e que seu sucesso ou fracasso depende também da atuação dos agentes envolvidos diretamente nessa etapa.

Assim, o processo de implementação de políticas públicas deve ser entendido como um conjunto de interações entre os agentes implementadores e os destinatários dessas políticas. Esse processo possibilita mudanças e aprendizagem no campo das políticas públicas através dos valores e ideias individuais de cada agente que, ao atuar, acaba gerando algumas transformações no programa.

Uma vez que o foco dos estudos nessa perspectiva está em compreender o que acontece na base da implementação e quais suas influências e transformações no processo de operacionalização das políticas, deve-se, primeiramente, entender como e por que a discricionariedade que os agentes de base são capazes de exercer na burocracia governamental é a chave de todo o processo de implementação de políticas. É nessa linha de pensamento que Lipsky (1980) buscou desenvolver sua teoria, conhecida como Street-level Bureaucracy, que trata da atuação dos burocratas no processo de implementação, principalmente dos burocratas implementadores ou agentes públicos de base.

O termo burocracia no nível da rua, tradução literal da expressão cunhada por Lipsky (1980, p.3), diz respeito aos "servidores públicos que interagem diretamente com os cidadãos no curso de seus empregos, e que têm critério substancial na execução de seus trabalhos". Para o autor, os típicos burocratas de rua seriam aqueles empregados públicos que concedem o acesso a programas do governo e fornecem serviços dentro desses programas. Professores, policiais, profissionais da saúde, assistentes sociais são alguns dos exemplos clássicos descritos em suas pesquisas. 
Lipsky (1980) demonstra a importância desses agentes que, por serem fornecedores dos serviços e bens públicos aos cidadãos, são considerados o foco da controvérsia política. Enquanto, de um lado, são pressionados por suas agências para melhorarem a efetividade, de outro, são pressionados por grupos de cidadãos para aumentarem a eficiência e eficácia dos serviços públicos.

Na visão de Lipsky (1980), a discricionariedade é uma característica central e estrutural da atuação do burocrata de rua. Para ele, esses agentes produzem grande impacto sobre as políticas públicas implementadas devido à autonomia que possuem no exercício de suas funções, cotidianamente. É por isso que, muitas vezes, uma mesma política pode produzir resultados totalmente diferentes em realidades diferentes.

Lotta (2010, p.4) faz uma observação interessante sobre o entendimento do poder discricionário desses agentes ao afirmar que "a discricionariedade exercida pelos burocratas é resultado da interação que exercem entre seus próprios valores, valores de outros atores envolvidos, os procedimentos, restrições, estruturas, incentivos, encorajamentos e proibições". Assim, é necessário examinar os padrões de interação para compreender por que as ações foram feitas daquela forma. A questão, portanto, é olhar para o ambiente institucional e relacional dentro do qual a burocracia opera.

O reconhecimento da discricionariedade implica em maiores chances de sucesso de uma política em contextos variados. Isso porque, ao conviverem diariamente com os problemas e situações reais dos cidadãos, os burocratas sabem exatamente qual a melhor maneira para aquela política atender determinado usuário e gerar efeitos positivos. O exercício da discrição é, portanto, fundamental e necessário, na medida em que as regras predefinidas formalmente não podem atender e resolver todos os casos concretos e, graças a isso, o poder discricionário do agente da base torna-se imprescindível para que os programas se ajustem à realidade, funcionem e atendam aos cidadãos.

\section{Um panorama sobre o Programa Bolsa Família}

Criado em 2003, o PBF é um programa de garantia de renda mínima com condicionalidades voltado para a redução e o combate à pobreza, presente nos 5570 municípios da Federação e atingindo 13,8 milhões de famílias (CAmpello; Neri, 2013). A existência de contrapartidas aumenta o vínculo das famílias ao programa, além de criar desincentivos à inércia dos beneficiários. Essas contrapartidas nas áreas de saúde e educação acionam uma complexa logística de provisão de bens e serviços sociais, envolvendo um grande número de agentes públicos que, na ponta, 
detém grande poder discricionário - aí incluídos os profissionais da educação, que podem exercer papel decisivo na condução do programa em nível local.

No nível central, a coordenação do programa compete ao Ministério do Desenvolvimento Social e Combate à Fome (MDS). Na ponta, a gestão do PBF é realizada pela secretaria da área onde ele está localizado (Assistência Social, Educação, Saúde e Planejamento, entre outras), de acordo com determinação do Poder Executivo municipal.

Como o programa envolve diversos órgãos em níveis distintos de governo, há diversos fluxos entre esses setores que promoverão alterações em seu funcionamento e nas definições de seus processos. O esquema a seguir apresenta as diversas instâncias e áreas envolvidas nos governos federal, estadual e municipal, com ênfase nos momentos de transformação que a política sofre cada vez que uma mudança de nível acontece até chegar ao nível local:

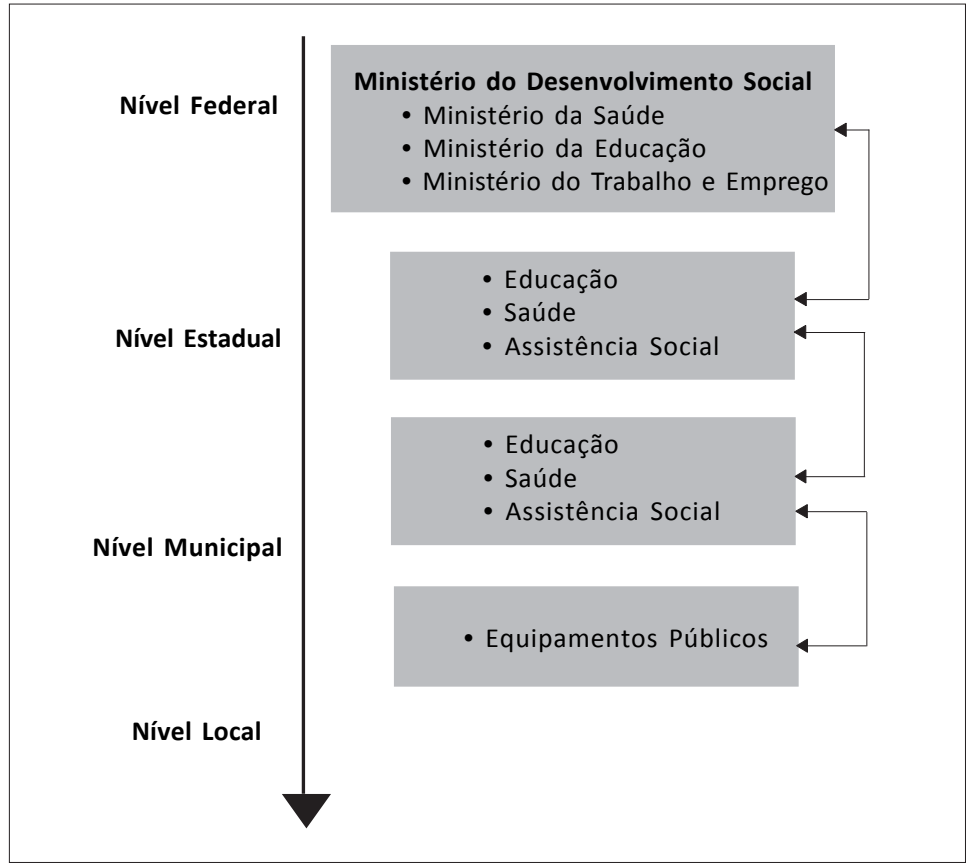

Fonte: Elaboração própria, adaptado de Lotta (2010).

Figura 1: Níveis hierárquicos e fluxos de transformação do Programa Bolsa Família

O PBF é um programa centralizado em termos orçamentários e descentralizado no que toca à sua operação. Segundo Neri (2003), há duas visões favoráveis e complementares sobre a descentralização operativa e a centralização orçamentária nesse programa. A primeira afirma que os governos locais são os que têm 
melhor condição de identificar e acompanhar as demandas da população mais pobre, elevando os ganhos de eficiência alocativa. A segunda ressalta que os municípios devem receber recursos adicionais para que sejam capazes de realizar a operação e o monitoramento do programa, uma vez que, sem capacidades institucionais locais, o programa correria sério risco de perder suas principais características.

Além de ser o detentor da verba orçamentária do programa, o Executivo federal é responsável por diversos processos-chave: definir as famílias que serão beneficiadas; gerenciar estrategicamente as informações contidas no Cadastro Único (CADU) ${ }^{1}$ e gerenciar a estrutura de incentivos aos governos locais por meio do Índice de Gestão Descentralizada (IGD)².

Ao mesmo tempo em que o Governo Federal blindava o programa em relação ao orçamento, impedindo que estados e municípios demandassem suas fatias, o MDS delegou às administrações municipais responsabilidades operativas, vinculando as prefeituras ao Governo Federal. A fim de estimular a gestão local, aumentar os indicadores de eficiência na ponta e reduzir as possibilidades de captura em uma típica relação agente-principal, o Ministério passou a repassar aos municípios recursos orçamentários - via IGD - que deveriam ser utilizados exclusivamente na operação do programa. Ao assegurar esses recursos aos municípios, especialmente aos menores e mais pobres (e que, em tese, seriam os que mais precisariam de apoio), o Governo Federal reduziu as possibilidades de que o programa sofresse desvios de rota que colocariam seus objetivos em xeque.

Ao atribuir claramente, desde o início do programa, as competências aos municípios, a participação dos estados era incipiente, senão inexistente. 0 governo, em 2010, percebeu que o esvaziamento da participação dos estados estava trazendo prejuízos ao programa, tanto do ponto de vista político quanto operacional. $\mathrm{Na}$ esfera política, o MDS encontrava resistência dos estados para desempenharem o papel de coordenação de seus municípios, uma das maneiras encontradas para minimizar os problemas de comunicação e articulação com as esferas locais. Naquele ano, o IGD foi decomposto em IGD-E (estadual) e IGD-M (municipal), de modo que os estados também passaram a receber recursos do MDS que poderiam ser aplicados em atividades afins à operação do PBF.

\footnotetext{
${ }^{1}$ O CADU é um instrumento de coleta de dados que tem como objetivo identificar todas as famílias em situação de pobreza existentes no país.

${ }^{2} \mathrm{O}$ IGD é um indicador que varia de zero a um e mostra a qualidade da gestão do PBF no âmbito municipal através de um repasse que, atualmente, pode ser, no máximo, de $\mathrm{R} \$ 3,25$ por família beneficiária. Com esse mecanismo de incentivos, o MDS coordena a ação dos municípios, assegura que os procedimentos administrativos e operacionais sejam minimamente cumpridos e apóia financeiramente os governos locais.
} 
Mesmo que o município não seja o responsável pela gestão do CADU, claro está que os agentes públicos que estão na ponta, encarregados de analisar o perfil dessas famílias, são os que, na verdade, decidem quem serão - ou não - potenciais beneficiários de uma bolsa. Também serão esses agentes os encarregados de prover os serviços de saúde e educação necessários para que as famílias satisfaçam os requisitos do programa. Em um programa tão descentralizado como o Bolsa Família, o que de fato importa é qual é o entendimento e a posição de quem está na ponta, tanto no nível municipal quanto na interface com o cidadão.

\section{A implementação de políticas sociais no nível local: os equipamentos públicos ${ }^{3}$, o PBF e os agentes de base}

Especificamente em relação às organizações, Selznick (1966) destaca a estrutura interna informal das instituições. São nessas estruturas informais que os diversos grupos de interesse ou agentes individuais definem estratégias utilitaristas com o objetivo de maximizar poder, prestígio e vantagens materiais, ou se defendem contra a alienação, em suas várias formas.

No nível local, os equipamentos podem ser considerados tipos de organizações públicas, razão pela qual correspondem às formulações de Selznick (1966). Nesse sentido, a contribuição de Crozier (1981) sobre as organizações pode ser estendida àqueles espaços: são uma arena política sui generis onde as opiniões, impressões e valores dos profissionais que neles atuam - e de outros que a eles se agregam temporariamente, como os assistentes sociais e profissionais da saúde, por exemplo - se encontram e se combinam. Por isso, as especificidades de cada equipamento no nível local (os hospitais, as delegacias, os centros comunitários de saúde e de assistência e as escolas, entre outros) revelam particularidades que, apesar de fazerem parte de um sistema burocrático, impedem maiores generalizações. Os resultados dessa "alquimia" são inúmeros, mas fundamentais para se compreender como as decisões são tomadas por esses profissionais e quais as implicações dessas ações no desenho institucional das políticas públicas sociais.

\footnotetext{
${ }^{3}$ Segundo o Decreto no 7341, de 22 de outubro de 2010, consideram-se equipamentos públicos comunitários as instalações e espaços de infraestrutura urbana destinados aos serviços públicos de educação, saúde, cultura, assistência social, esportes, lazer, segurança pública, abastecimento, serviços funerários e congêneres.
} 
Nessa direção, as pesquisas sobre redes têm avançado e se multiplicado nas últimas décadas, especialmente quando a sociologia passa a interessar-se pelos microprocessos que envolvem as relações entre grupos sociais, entidades e indivíduos. Marques (2012) faz uma compilação das publicações na área, indicando, entre outros, estudos sobre processos de migração, pobreza e segregação em espaços metropolitanos; sobre construção e quebra de relações sociais; esferas de deliberação em espaços urbanos; as redes no mundo dos negócios; a busca por emprego e o impacto de políticas públicas sobre redes comunitárias.

Segundo Marques \& Moya (2012), as redes sociais compõem o tecido das relações entre indivíduos, grupos e entidades na sociedade, estruturando os campos em que os fenômenos sociais acontecem. Em escala microssocial, as relações construídas cotidianamente pelos atores sociais exercem influência sobre a sociabilidade desses agentes, afetando a forma como resolvem seus problemas e buscam ajuda, onde e como encontram trabalho e onde se constroem e transformam laços sociais. Em outra dimensão, a teia constituída pelos vínculos entre indivíduos, grupos e organizações define as relações de poder e os conflitos presentes no estado e em seu entorno imediato, envolvendo todas as partes interessadas.

Em relação às escolas, Nóvoa (1991) afirma que a autonomia desses espaços combina elementos de ordem profissional e institucional na medida em que a escola é "promovida" à organização detentora de poderes e capacidades para definir as regras do jogo com seus diversos stakeholders, os distintos segmentos que participam e constituem a chamada comunidade escolar. Pais, professores, alunos, profissionais da educação, vizinhos, bairro, burocratas da secretaria de educação e de outras secretarias, outros bureaus, sindicatos e organizações sociais, editoras, produtores de alimentos, políticos, entre outros, são algumas de suas partes interessadas. Dessa forma, institucionaliza-se não apenas a autonomia dos profissionais da educação, mas também a dos alunos e de suas famílias, além da comunidade que está distribuída ao redor da escola.

Ao mesmo tempo em que fazem parte da macroestrutura do sistema burocrático educacional - a grande agência -, as escolas operam como micro bureaus em função da natureza de sua operação. Conforme exposto por Evangelista e Shiroma (2007), as reformas educativas têm contribuído para a coletivização do trabalho dentro e fora da escola, fazendo com que os diversos profissionais participem de várias esferas decisórias que vão desde a formulação do projeto pedagógico até o planejamento transversal dos currículos, passando pelos órgãos internos e externos de representação colegiada que agregam as políticas sociais e as diversas partes interessadas, os stakeholders. 
Ao analisar essa questão para o contexto das unidades escolares, Derouet (1995) acrescenta a dimensão da extraterritorialidade, que também pode ser estendida aos demais equipamentos. "Os agentes públicos, submetidos a um controle longínquo e, de qualquer maneira, interno à sua corporação, perdem o sentido de serviço a prestar, e a máquina acaba por funcionar em "roda livre", ou seja, no interesse dos próprios profissionais" (Derouet, 1995, p.75). Segundo o autor, o único meio de fazer com que os professores redescubram sua missão é confrontá-los com a procura social, com o local e com os desdobramentos que a interação com os demais agentes proporcionará.

Segundo Marques \& Moya (2012), os agentes que estão na base estabelecem vínculos que unem seu grupo social a outros, independentemente da localização. Em outras palavras, esses atores constroem pontes em seu território com os colegas que lá estão (outras escolas, centros de saúde, igrejas, creches e outros espaços-referência), mas não se limitam a ele. Pelo contrário, têm relações com outros agentes em diferentes esferas do setor público e do terceiro setor.

Quanto mais intensa e expandida for essa rede, maior a possibilidade de novos círculos serem criados. Os agentes que fazem essas pontes tendem a estar na fronteira de seu respectivo grupo social, desempenhando uma função estratégica. Nesse sentido, a qualidade e a profundidade desses vínculos poderão indicar o estoque de capital relacional de cada um desses profissionais, reforçando a tese de que tais arranjos são muito heterogêneos e dinâmicos.

Ainda que utilizem métodos de investigação diferentes, os resultados das pesquisas de Marques (2012) e Lipsky (1980) são convergentes, indicando que as relações sociais, mesmo em espaços com elevado grau de institucionalização, continuam mediando o acesso entre as organizações públicas e entre elas e o cidadão. Pode-se, portanto, afirmar que as políticas públicas acabam induzindo e estimulando esse tipo de interação em nível local, permitindo que sucessivas trocas aconteçam entre os agentes envolvidos. A política pública, então, também será resultado dessas combinações.

Assim, a escola, do ponto de vista organizacional, abandona estruturas verticais e rígidas e passa a operar a partir de processos flexíveis, horizontais e dinâmicos. Em outras palavras, as escolas deixam de ser burocracias hierarquizadas, autoritárias e rígidas e passam a ser burocracias coletivizadas e mais participativas. É nesse espaço que os profissionais da educação, em especial os professores, de acordo com a teoria de Lipsky (1980), atuam como burocratas.

Em relação ao $\mathrm{PBF}$, os processos desse programa que passam pela escola poderão sofrer distorções ou modificações feitas pelos docentes ou por outros atores 
envolvidos nesse espaço. Essa ressignificação exercida pelos atores escolares, na outra ponta da formulação de políticas, é elemento constituinte dessas mesmas políticas, não podendo ser ingenuamente ignorada pelos gestores dos programas propostos.

\section{Metodologia}

Este é um estudo de natureza qualitativo-exploratória, que analisou o processo de implementação do PBF em uma região de pobreza extrema de Belo Horizonte. É importante ressaltar que não se pretende, com este estudo, produzir ou alcançar padrões gerais, categorizações ou classificações, ainda que se possa, segundo Franco (2000), chegar a construir o objeto científico no âmbito do particular ou do geral. Em outras palavras, deve-se salientar que as análises aqui empreendidas limitam-se aos dados empíricos coletados a partir dos recortes realizados. Por outro lado, ainda que as generalizações não sejam possíveis, estudos dessa natureza permitem mergulhar nas especificidades do campo, revelando a complexidade das relações e das variáveis que conformam a realidade observada.

Os procedimentos metodológicos adotados a priori foram: análise documental e coleta de dados sobre a arquitetura do programa e sua implementação; entrevistas informais com agentes responsáveis pelo programa nos níveis federal e local para a definição das pré-categorias analíticas; elaboração e teste dos questionários; seleção de duas escolas públicas municipais localizadas em uma região de pobreza extrema; seleção e entrevista com os agentes de implementação envolvidos; análise das entrevistas e demarcação das categorias.

A análise dos dados sobre o PBF subsidiou a elaboração dos roteiros para as entrevistas que foram realizadas. Três níveis de governança do programa foram definidos: estratégico nacional e local (MDS e Prefeitura de Belo Horizonte); gerencial (gerentes setoriais na regional administrativa municipal) e operacional na ponta (profissionais da educação, assistentes sociais e agentes de saúde, em dois bairros de uma região de pobreza extrema da cidade).

Roteiros semiestruturados para as entrevistas com os agentes em nível estratégico no MDS e na Prefeitura foram elaborados de forma a contemplar as seguintes categorias: (1) percepção do programa; (2) valores e representações sobre o público-alvo; (3) percepção sobre a ação dos governos; (3) desenho institucional e operativo do programa; (4) impressões sobre as condicionalidades do programa e as exigências para os agentes em nível local; e (5) as rotinas dos agentes no cotidiano da política. 
Os roteiros foram adaptados para diferentes sujeitos, dependendo de seu envolvimento e posição na hierarquia do programa. Foram realizadas 31 entrevistas, assim distribuídas: (quatro) corpo estratégico do programa - MDS; (duas) corpo estratégico do programa - Prefeitura de Belo Horizonte; (três) corpo gerencial do programa - Regional Administrativa Municipal; (14) agentes públicos na ponta profissionais da escola (diretores, professores e coordenadores pedagógicos em duas escolas); (oito) agentes públicos na ponta - profissionais da assistência social em dois centros de referência em assistência social (CRAS).

\section{O PBF: a implementação na cidade de Belo Horizonte}

Belo Horizonte é uma cidade considerada referência na gestão de políticas sociais porque tem avançado no modelo de redes de proteção social, tendo acumulado expertise que tem sido compartilhada com outros estados e municípios, além de com o próprio Governo Federal. Desde 1994, a cidade tem sido governada por coalizões de centro-esquerda, dando às políticas sociais linearidade e consistência, o que permitiu à administração municipal desenvolver certo knowhow no acompanhamento das famílias.

O PBF está abrigado na Secretaria Municipal de Política Social (SMPS). Segundo uma das entrevistadas em posição intermediária, diversas são as dificuldades de interlocução e operação enfrentadas, especialmente no que diz respeito ao monitoramento das condicionalidades e à concretização da rede de proteção social no município, que, no nível central, envolve as secretarias de saúde, educação e assistência social.

A gestão do PBF é realizada em três níveis hierárquicos, com a participação dos setores envolvidos em cada nível, horizontalmente. No nível central, a Câmara Intersetorial de Política Social (CIPS) é composta pelos secretários municipais de cada uma das áreas envolvidas e pelos subsecretários de cada regional administrativa. Algumas políticas, como o Bolsa Família, têm grupos temáticos dentro da câmara. Participam do Grupo Temático (GT) Bolsa Família representantes em nível estratégico das secretarias de educação (SMED), saúde e assistência social.

No segundo nível, há o Núcleo Intersetorial Regional (NIR), com os gerentes regionais de cada uma das secretarias. Cada uma das nove regionais tem seu NIR. O Bolsa Família é um dos programas que integra a agenda de acompanhamento do núcleo. No nível local, a articulação acontece através dos grupos temáticos locais, ocupados pelos gerentes ou diretores dos equipamentos públicos naquele território (centros de saúde, CRAS, escolas, centros comunitários). A Figura 2 apresenta essa estrutura de governança. 


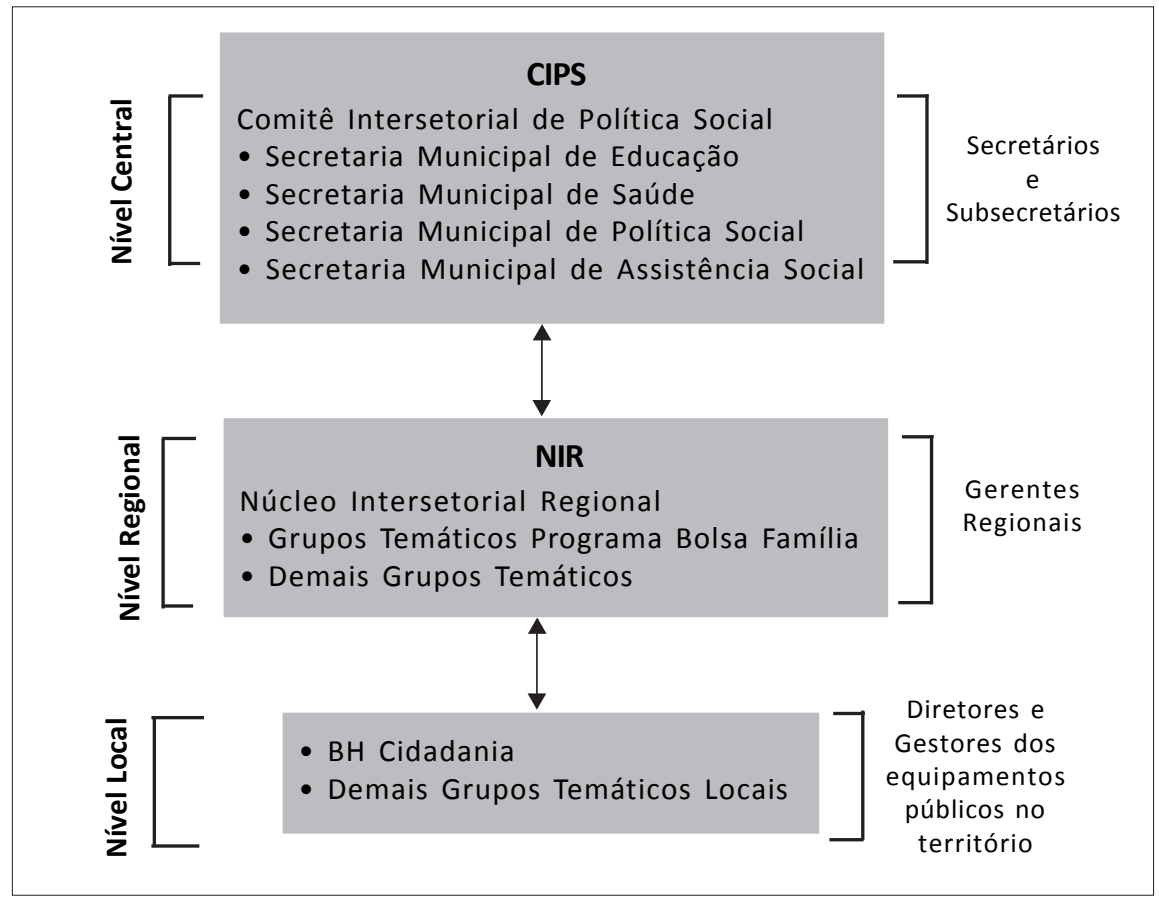

Fonte: Elaboração própria.

Figura 2: Estrutura de governança das políticas sociais em Belo Horizonte

Além das dificuldades de articulação - compreensíveis quando a cultura de redes de políticas intersetoriais ainda é frágil no Brasil -, questões referentes ao monitoramento da condicionalidade educacional parecem tornar a implementação mais complexa, tensionando a relação entre as áreas.

O controle da frequência escolar é um processo repleto de procedimentos burocráticos, que geram desdobramentos importantes. Em linhas gerais, cabe à escola apurar a frequência e alimentar o SGE, vinculado ao Ministério da Educação (MEC). Com base nesse sistema, o MDS levanta o número de famílias que estão em situação irregular na condicionalidade educacional. Feito isso, cada município recebe uma relação dos beneficiários que devem justificar as ausências. Paralelamente a isso, cada família recebe uma notificação do MDS, devendo, então, apresentar um recurso, processo no qual apresentam os motivos pelos quais seus filhos obtiveram, naquele período, faltas acima do limite permitido. Os recursos são analisados pelos setores municipais designados e seu resultado é inserido no CADU, regularizando a pendência. Dependendo da situação, a família pode ser suspensa, desligada, mantida em observação ou liberada. 


\section{O desenho do programa na perspectiva dos agentes públicos de base: os desafios e dificuldades enfrentadas}

Uma das principais características dos agentes públicos que estão em nível local é a elevada discricionariedade presente no cotidiano desses indivíduos. Em outras palavras, apesar de os agentes públicos que estão na ponta ocuparem posições hierárquicas inferiores no fluxo de implementação, a proximidade com o cidadão/beneficiário potencializa a capacidade decisória daqueles sujeitos.

No caso do PBF, percebeu-se que o desenho do programa contém brechas ou instruções vagas, permitindo ou potencializando sua interpretação; a falta/ impossibilidade de controles administrativos e/ou observação/acompanhamento sistemático do trabalho dos agentes contribui para o empoderamento desses atores; os agentes públicos de base observados desenvolvem ou acumulam expertise ao longo do tempo, ajustando-se às rotinas existentes e/ou desenvolvendo estratégias de atuação a fim de melhor desempenharem seu trabalho ou driblarem constrangimentos impostos pelas instituições às quais estão submetidos; e o capital relacional acumulado por esses atores é uma variável importante para explicar como a discricionariedade é exercida, especialmente quando as redes de interação são consideradas.

Há relatos que indicam que os agentes de base tomam decisões em consonância com o que acreditam, com seus valores e crenças, ultrapassando os limites muitas vezes impostos pela falta de recursos. Uma das assistentes sociais entrevistadas discorre sobre o dilema gerado pelo uso da discricionariedade entre os profissionais do CRAS, uma das questões apontadas por Lipsky (1980). Independentemente da complexidade do que deliberam, suas decisões têm implicações diretas na vida das pessoas que são por elas atendidas. A partir do exemplo da cesta básica, em que cada um dos agentes públicos deve decidir se o requerente satisfaz - ou não - os requisitos definidos para receber os alimentos, nota-se que o comportamento desses sujeitos pode produzir distorções quando o poder a eles conferido é exercido. Cada um decide e usa o poder que tem tacitamente. Nesse caso, percebe-se que não há uma regra oficial ou institucionalmente definida; pelo contrário, o bom senso é o critério que orienta a ação desses indivíduos, ampliando a subjetividade do processo.

Coordenadora do CRAS B: A cesta-básica é um nó. É uma relação de poder que é dada para o técnico de avaliar se a família terá ou não acesso à cesta. Eu vou dar a cesta ou não vou dar a cesta? Aí você começa a criar mecanismos para tentar igualar o atendimento. Porque aí um fala assim: tem família que todo mês ela está precisando sim. Aí o outro diz: mas tem família que é muito preguiçosa. 
É interessante notar que, ao deparar-se com o dilema que a situação recorrente revela, tenta-se definir um padrão para evitar que os atendimentos sejam díspares, apesar de uns serem mais permissivos e outros mais rigorosos. Os agentes também tomam decisões a partir da experiência que vão acumulando ao longo do tempo, o que dá a eles condições de ajustarem seus critérios em função das situações que se apresentam. Como a rotina desses atores é repleta de imprevistos, esses elementos acabam colaborando para que suas estratégias sejam conformadas. Em outras palavras, aprendem fazendo. Ao desenvolverem essa expertise, criam suas próprias regras e códigos de conduta que serão validados ou aprimorados à medida que novas demandas emergirem.

Assistente social CRAS A: A gente é que está na ponta, que atende o usuário, que está ali frente a frente com ele, com a família. Cada caso é um caso diferente que você atende. A partir daí você desenvolve uma técnica para trabalhar com essas famílias.

A discricionariedade dos agentes tem relação direta com o desenho das políticas e com a forma como os procedimentos e rotinas são definidos e executados. Há uma distância entre aqueles que definem as regras e aqueles que as cumprem/ executam. Assim, uma das características da burocracia pública, segundo Wilson (1989), Moody \& Musheno (2003) e Lipsky (1980), é a impossibilidade de controle administrativo e/ou observação/acompanhamento sistemático do trabalho de certos agentes públicos, especialmente aqueles envolvidos nas áreas sociais, com maior proximidade do cidadão/usuário.

Duas passagens evidenciam como os agentes categorizam os usuários/públicoalvo. Na primeira, a diretora comenta sobre como sua decisão é influenciada pela informação que tem sobre determinada mãe ou pelo fato de conhecer - ou não seu perfil. Dá a entender que, porque conhece as mães dos alunos de sua escola, a chance de acatar a justificativa de ausência apresentada por mães sérias e comprometidas com a educação de seus filhos é maior:

Diretora Escola A: A gente acaba conhecendo a mãe. Conheço a história de vida dela, sei que ela trabalha, cria os filhos da melhor maneira que pode, então não deixa os meninos faltarem. Ela pisou na escola para justificar, eu já conheço. A gente acaba cometendo esse juízo de valor.

Conforme relatado na seção anterior, o monitoramento da frequência escolar produz modificações na rotina dos agentes que estão na base. Uma das profissionais que atuam nesses equipamentos relata que a falta de treinamento ou informação sobre como proceder é uma das dificuldades enfrentadas. Nesse 
caso, tais assimetrias de comunicação ampliam a discricionariedade desses sujeitos e produzem diferentes entendimentos sobre como proceder, que podem modificar os processos burocráticos realizados por esses profissionais. Há, também, dificuldades que se materializam quando as rotinas dos profissionais do CRAS e da escola se cruzam por conta da condicionalidade educacional. Como a escola é a responsável pela informação sobre as faltas e cabe ao CRAS processar os recursos que são gerados a partir da informação fornecida pela escola, o hiato entre o levantamento da frequência e o processamento das justificativas compromete o atendimento qualitativo das famílias e reforça a dimensão burocrática dos processos, conforme o trecho de entrevista a seguir.

As tensões descritas entre as secretarias municipais também são percebidas pelos agentes que estão na ponta. Em relação aos recursos, os assistentes sociais questionam se deveria ser o CRAS o responsável por essa rotina, uma vez que, para eles, o acompanhamento qualitativo da frequência escolar dessas crianças deveria ser uma atribuição da escola. Além disso, esses agentes afirmam que o acompanhamento da frequência produz outros desdobramentos que estão ligados ao cotidiano da escola, como questões relacionadas ao desempenho dos alunos, a relação que têm com a escola e os vínculos com as famílias.

Por outro lado, a escola não abre mão de ser a responsável pela análise das justificativas que as famílias apresentam quando seus filhos faltam, antes de os dados serem definitivamente inseridos no sistema de gestão. Se o aluno se ausentou, os responsáveis devem comunicar o(s) motivo(s) à secretária escolar, que decidirá se acatará ou não a justificativa. A entrevista com a secretária escolar evidencia isso:

Secretária escolar: Esse aluno é nosso. E ele está aqui com a gente e você, querendo ou não, conhece a historia de vida desse menino. Muitas vezes você conhece pai e mãe, tio, papagaio e periquito. Então ninguém melhor para dizer o que está acontecendo.

Em relação à rotina desses atores, as entrevistas revelam como o dia a dia desses profissionais é atribulado e intenso. Recursos para processar, visitas para realizar e atendimentos diários são parte das atribuições desses agentes. Para desempenharem essas funções, contam com uma equipe reduzida e enfrentam as limitações de recursos que são típicas no setor público. Como descrito por Lipsky (1980), esses agentes ajustar-se-ão às condições que lhes são impostas, definindo critérios e estratégias de ação que não necessariamente farão com que o trabalho seja desempenhado da maneira mais eficaz e eficiente. Esses sujeitos passarão a definir suas prioridades à medida que as demandas e urgências se apresentarem, correndo o risco de serem absorvidos pelo volume de tarefas que devem cumprir. 
Uma das entrevistadas relata sua preocupação com a segurança da equipe, uma vez que o equipamento situa-se em região de elevada marginalidade. Nesse caso, o dilema orbita em torno das denúncias feitas por beneficiários, quando percebem que outras famílias recebem benefícios maiores que os seus. Ao comparecerem ao CRAS e sugerirem que tais famílias podem ter fornecido informações incorretas e que, por isso, estão recebendo mais do que deveriam, esperam que os agentes públicos denunciem tais práticas e façam com que os valores sejam suspensos ou revisados. Porque têm medo de retaliações, os profissionais do CRAS são cuidadosos nessas situações, mesmo sabendo que essa é uma de suas atribuições, como representantes do poder público:

Assistente social CRAS A: A gente nunca denuncia. A gente não pode. Porque uma vez que se identificar que a família perdeu o benefício e ela pensar que foi o CRAS que cortou, pode vir aqui e criar confusão com a gente, a gente está num território que tem violência, tráfico... é uma maneira de nos protegermos também.

Tanto as tensões geradas por causa dos processos de acompanhamento e monitoramento das condicionalidades quanto as dificuldades enfrentadas pelos agentes podem estimular a cooperação. A próxima seção tratará dessas duas dimensões.

\section{A intersetorialidade das políticas públicas e sua articulação: a visão dos agentes em nível local}

Assim como nos níveis central e intermediário, os atores que operam na ponta identificam tensões entre os setores da administração envolvidos com a implementação do programa. Algumas dessas tensões têm relação mais próxima com o desenho do PBF e suas rotinas administrativas, com o papel desempenhado por outros agentes de base que se encontram em outros setores (mas também na ponta) e com dificuldades de disseminação da informação e capacitação.

As entrevistas com os agentes indicam que a articulação entre os envolvidos no nível local não segue um padrão. O trabalho realizado pelos equipamentos públicos responsáveis pelo cumprimento, monitoramento e acompanhamento das condicionalidades do PBF tem graus variados de cooperação intersetorial. A relação entre o CRAS e a escola é marcada por dificuldades de convivência, de entendimento das respectivas rotinas e suas especificidades. Para a equipe de assistência, os profissionais da escola são distantes e resistentes à cooperação porque estão comprometidos com as atividades pedagógicas que desempenham na escola. Como não percebem (ou percebem, mas preferem ignorar tal atribuição) 
que seu trabalho poderia extrapolar os limites da escola, a participação desses profissionais nas arenas de deliberação e articulação que existem nos territórios é reduzida, senão inexistente.

É interessante destacar que, nesse nível, a rede de proteção social municipal perde seu caráter institucional. Os equipamentos públicos que operam localmente são, em última instância, o elo com a administração pública, compondo o complexo sistema que é a máquina governamental, conforme destacado por Marques \& Moya (2012). A rede, nesses casos, é muito mais alimentada pelos vínculos pessoais do que por questões institucionais, conforme o exemplo a seguir. Tendo-se em conta a análise bottom-up aqui empreendida, há que se considerar se, de fato, tal rede intersetorial existe:

Assistente social CRAS A: No papel é muito bonito... você lê, assim mas não funciona porque às vezes você chama a escola, ela não vem, às vezes você chama a saúde, ela não aparece. Chama, mas não aparece, aí você liga para articular uma visita junto com a saúde, ela nunca pode ir. Então isso não acontece, essa rede, essa intersetorialidade.

Como consolidar uma rede de cooperação intersetorial se os agentes públicos que estão na ponta têm rotinas tão diferentes; atendem públicos distintos de acordo com as especificidades de sua área de atuação? O trabalho realizado pelos centros de assistência é complexo e é desconhecido pelos profissionais da escola. Mesmo que haja sobreposição das famílias atendidas por esses espaços (uma vez que estão no mesmo território e estão muito próximos um do outro), a finalidade de cada um desses equipamentos produz entendimentos e percepções diferentes sobre as famílias e seus membros. As entrevistas realizadas dão algumas pistas para melhor compreender por que, às vezes, as relações são conflitantes. Para os profissionais da assistência, seu público-alvo é a família e, muitas das vezes, os titulares adultos dos benefícios. Os da educação, por sua vez, estão historicamente comprometidos com as crianças (ou jovens), seus alunos, mesmo que a SMED venha se esforçando para desenvolver estratégias que alcancem as famílias.

São, portanto, dois universos diferentes, atuando no mesmo espaço. Como têm interesses convergentes, é possível identificar os esforços que a equipe de assistência faz para compreender a ausência da escola nos espaços de discussão e deliberação que existem no nível local. Assim como os CRAS têm uma rotina muito diversificada e com muitas demandas, esses sujeitos inferem que o mesmo se passa com a escola e, ainda que construam suas referências de forma empírica e fragmentada, reconhecem a diferença entre eles. Professores podem trabalhar em mais de uma escola e/ou têm horários variados na escola, diferentemente dos profissionais de assistência, que, geralmente, têm jornadas fixas e regulares. 
Nessa mesma direção, a natureza do trabalho desses agentes é muito diferente entre si. Os profissionais da educação têm um tipo de formação; os da assistência têm outra. Seus olhares são distintos. Cada um tem seu ethos profissional e ideológico, que pode explicar porque tais modificações na dinâmica das escolas ainda levarão algum tempo para se efetivar (se é que isso vai acontecer). Talvez por isso, parece haver resistência dos professores em participar mais direta e proximamente das rotinas que o acompanhamento intersetorial das condicionalidades impõe.

\section{Percepções dos agentes sobre o PBF e suas condicionalidades}

A ação dos agentes públicos de implementação materializa a ação do Estado nas redes de interação que vão se configurando localmente, não apenas entre si, mas entre aqueles e os cidadãos. Em função da discricionariedade que é inerente ao comportamento desses profissionais, o burocrata em nível local pode distribuir e alocar os recursos de que dispõe para conferir mais ou menos acesso às políticas, tanto sob a perspectiva do cidadão quanto do setor público. Esses sujeitos podem ser elos fortes - ou fracos - na construção desses padrões de interação, aproximando - ou afastando - os usuários da arena pública. A fronteira entre o Estado e a sociedade pode ser, portanto, mais ou menos porosa, dependendo da forma como esses atores estabelecem suas relações com a população atendida.

De acordo com Lotta (2010), os estudos sobre implementação de políticas têm sugerido que as atitudes, valores, expectativas e crenças dos agentes de base podem ter impactos substanciais sobre o resultado das mesmas. A autora afirma que a forma como os burocratas de rua entendem, interpretam e percebem o desenho, os objetivos e as regras operativas das políticas exerce influência sobre como tais ações serão por eles executadas.

No que se refere ao Programa Bolsa Família e à condicionalidade educacional, a percepção dos assistentes sociais é convergente: todos concordam que o programa configura-se como um direito social oferecido à população mais pobre e vulnerável, que a corresponsabilidade com a escola é um elemento importante para dar coesão ao programa, que a escola amplia o capital social e cultural dos bolsistas e de suas famílias e que a inserção no espaço escolar serve como uma rede de proteção para esses sujeitos, diminuindo as chances de serem capturados pela marginalidade. Em relação aos profissionais da educação, tal consenso não foi identificado. Pelo contrário, há percepções favoráveis e desfavoráveis, conforme apresentado a seguir: 


\section{Percepções positivas}

Coordenadora escola B: Tendo o aluno dentro da escola, a gente consegue fazer tudo. É o Bolsa que consegue fazer o aluno estar dentro da escola.

Professora escola A: O menino fica na escola porque senão corta o Bolsa Família dele. Agora faz diferença por causa da questão financeira. Então, para esse menino isso está dando resultado.

Coordenadora escola A: "Olha meu filho, não é só o tráfico que dá dinheiro. Você pode ser um tanto de coisa interessante quando você crescer". Então eu acho que, para os excluídos, foi muito legal. Dá trabalho para o professor? Dá. Tem professor que não aguenta? Tem. Até porque a gente não foi preparada para isso.

\section{Percepções negativas}

Professora escola A: Estou dizendo que não concordo com esse programa. Não sou a favor desse paternalismo [sobre receberem para matricularem seus filhos na escola].

Secretária escolar: Eu acho um absurdo pagar para a mãe colocar a criança na escola. O governo está pagando para a mãe mandar o menino para escola. Para mim é o cúmulo. É uma obrigação da mãe colocar o menino na escola, não tirar o dinheiro do nosso bolso para a mãe fazer isso.

Professora escola B: O programa é muito assistencialista, muito paternalista. Às vezes, a gente pensa assim "aquela mãe, em vez de ela ter dois filhos, ela teve cinco, seis filhos para ter o Bolsa Família e não ter que trabalhar."

Nos trechos em que as percepções negativas foram destacadas, percebe-se a posição que os professores têm em relação à liberalidade do gasto e à dimensão da assistência social. Para esses entrevistados, o programa estimula a indolência e a preguiça. No entanto, a pesquisa de Oliveira e Soares (2013) comprova o contrário.

Mesmo tendo posições distintas sobre os objetivos do programa, não houve, nas entrevistas com esses profissionais, relatos que sugerissem algum tipo de discriminação explícita ou sanção em relação aos alunos beneficiários. Não há diferenciação entre os alunos no diário escolar. Os entrevistados afirmam não saber quem são os alunos do programa. Ainda que alguns professores tenham dito que "acabam sabendo por que a mãe procura e fala", parece que os professores não têm essa preocupação.

Mesmo não havendo referências explícitas a práticas discriminatórias, os trechos das entrevistas da secretária escolar e da professora da escola B reproduzidos permitem uma indagação: o fato de terem posições contrárias ao programa tem 
algum reflexo na forma como lidam com as rotinas de seu trabalho? Será que a secretária, pelo fato de ser refratária ao Bolsa Família, é mais rigorosa com as famílias, exercendo a discricionariedade que lhe é conferida como uma estratégia de controle e regulação?

Da mesma forma, será que a professora, porque acredita que o programa é assistencialista, é mais severa com os alunos bolsistas na apuração de suas faltas, na conferência e correção de suas atividades escolares, nas avaliações que realiza sobre esses alunos nos conselhos de classe e reuniões pedagógicas e na relação que estabelece com eles?

As entrevistas com professores e diretores não identificam restrições dessa natureza aos alunos. No entanto, há questões importantes em relação à natureza da condicionalidade educacional. Para alguns, o controle da frequência é suficiente, uma vez que o objetivo é incentivar a criança/o jovem a frequentar a escola, corroborando os achados de Oliveira e Soares (2013, p. 294), que afirmam "que há evidências de que o PBF reduz a repetência de quem o recebe".

Na direção oposta, sabe-se que há profissionais da escola que defendem que o programa exija desempenho escolar como contrapartida (ainda que nenhum dos que foram entrevistados afirme isso). Da mesma forma, cabe a pergunta: estariam esses profissionais dizendo que a exigência de desempenho escolar como uma condicionalidade daria ao programa um caráter educacional mais robusto? Poderia ser esse um mecanismo capaz de fazer com que os professores se envolvam mais com o acompanhamento dessas crianças e suas famílias?

\section{Como agem os agentes de base?}

Evans e Harris (2004) fazem uma excelente revisão de pesquisas que têm como objeto o papel dos agentes de implementação que atuam com programas sociais e o exercício da discricionariedade. Os autores afirmam que os estudos empíricos realizados comprovam a tese de Lipsky (1980) de que a política pública é, na verdade, o que os agentes que estão na ponta fazem. Uma pergunta emerge: a discricionariedade dos atores é boa ou ruim para a implementação da política?

A resposta é: depende. A Figura 3 apresenta quatro cenários (com os respectivos trechos de entrevistas que servem como exemplo), que sugerem as diferentes combinações e os desdobramentos possíveis a partir de duas dimensões: a discricionariedade dos atores em dois extremos e a qualidade do marco regulatório dessa política. Assumindo-se que, tecnicamente, seu marco regulatório é adequado ou não (O público-alvo é bem delimitado? Há vazamentos? Os objetivos estão claramente definidos? Os processos estão 
desenhados adequadamente?), os agentes públicos que trabalham com essas políticas podem adotar, simplificadamente, duas posições em que se expressa sua discricionariedade: apoio ou rejeição.

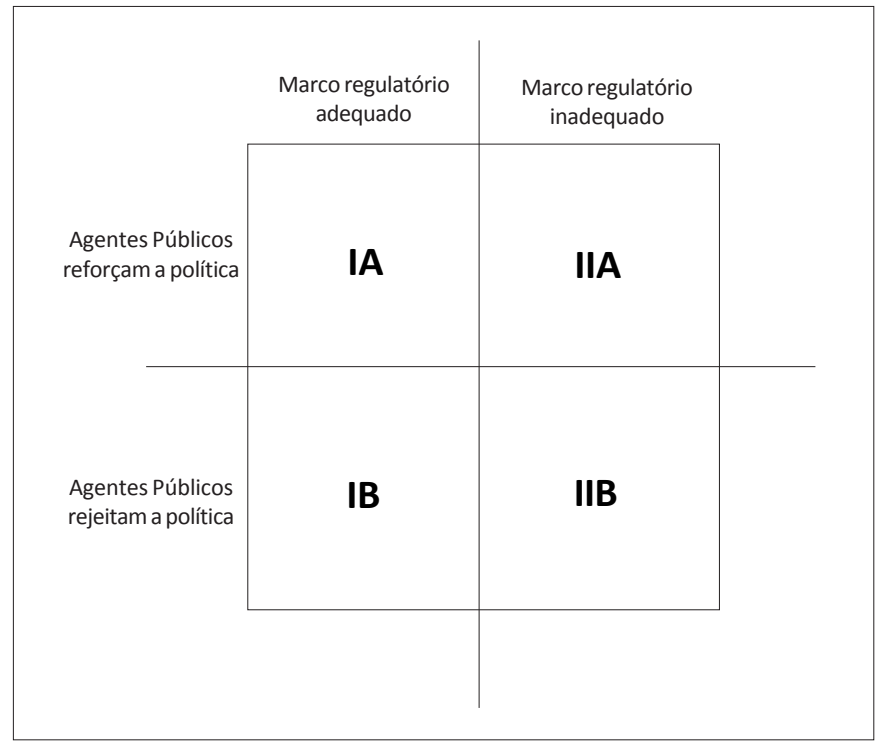

Fonte: Elaboração própria.

\section{Figura 3: Matriz de Atitudes}

Ainda que essas posições tenham um espectro largo entre esses extremos, quatro combinações permitem identificar algumas questões importantes:

\section{IA}

O quadrante IA parece, inicialmente, a melhor combinação possível, uma vez que a política é adequada e os atores cooperam. Entretanto, mesmo o fato de os indivíduos concordarem, aprovarem e cooperarem com a política não garante que seus limites serão respeitados ou que novos elementos sejam a ela incorporados. Os indivíduos podem ir além.

A gente fala que fica debaixo do nosso braço (...) [Assistente social do CRAS A usando uma expressão para explicar que não se esquece das famílias que atende]

A escola está aqui funcionando. Ele está lá fora. O lugar dele é aqui dentro [Coordenadora do Programa Saúde na Escola, referindo-se ao aluno do programa Bolsa Família] 


\section{IIA}

A combinação IIA, por sua vez, indica que, apesar de a política ter problemas, os agentes a reforçam. À primeira vista, poder-se-ia esperar que os atores não a reforçariam, tendo em conta que a política tem um marco regulatório inadequado. Entretanto, mesmo que o desenho seja problemático, os sujeitos podem agir no sentido de corrigir seu curso de ação cotidianamente, ajustando os problemas na medida em que são processados. Os agentes aprovam a política e/ou percebem que é importante em relação ao trabalho que desempenham. As entrevistas realizadas com os profissionais da escola indicam isso.

Eu tenho a vivência da escola, eles não. [Diretora da escola $A$, referindo-se à dinâmica da escola, em contraposição aos assistentes sociais]

A gente sabe é fuçando [Secretária escolar referindo-se aos procedimentos do programa Bolsa Família].

\section{IB}

O terceiro quadrante denota uma situação curiosa: se a política é boa, porque os agentes a sabotam? A discricionariedade aqui, à primeira vista, pode ser vista como um mal, uma vez que a proposta é boa. Entretanto, os agentes não a apoiam e, por isso, não a implementam como foi pensada. Por outro lado, podem usar seu poder discricionário para reforçar algum elemento na agenda governamental ou, para, por exemplo, pressionar o governo em relação a uma questão específica. Sacrificar a política poderia ser, nesse caso, positivo para o grupo.

Eu não estou aqui para resolver esse tipo de problema. [Professora da escola A, referindo-se a problemas ligados à pobreza, sua percepção sobre o programa e as limitações que impõe à sua atuação como agente pública]

Daqui a pouco vai querer dar o banho, né? [Secretária escolar, referindo-se, criticamente, às funções que a escola pública tem assumido e às expectativas crescentes que as famílias têm apresentado]

\section{IIB}

É claro que os agentes de implementação podem sabotar uma política que tenha desenho inadequado, como revela o quarto quadrante. Também não há como assegurar que isso seja bom ou ruim, uma vez que, por exemplo, a política pode ser "boa" e ter fragilidade em sua arquitetura - e a sabotagem dos agentes, nesse caso, "consertaria" essas imperfeições. Por outro lado, a sabotagem dos atores pode também redefinir a agenda do governo, forçando-o a redefinir a política. 
Se nunca me explicaram para que serve um GT [grupo temático], o que eu vou fazer lá? [Professora da escola B, sobre a participação em reuniões da Regional]

Eu acho que talvez a desculpa seja que se tem muita coisa para fazer na escola e que eles realmente não percebem que é papel deles. Como eu tiro um professor de sala de aula para entender quem é o aluno, a mãe, a família? Ele não tem tempo. [Coordenadora do CRAS A, sobre a dinâmica da escola e a falta de tempo dos professores]

A capacidade decisória desses atores reforça o seu papel político. Do ponto de vista da correlação de forças entre os diversos grupos que se encontram nas arenas onde as pressões políticas se materializam, a probabilidade de esses agentes estarem presentes é real. Professores, profissionais da saúde, policiais, etc. detêm poderes de agenda que não podem ser desprezados, ainda que se saiba que o capital político desses grupos não é o mesmo.

É por isso que não se pode afirmar que a discricionariedade desses atores será sempre utilizada para produzir valor unicamente para o cidadão, porque, dependendo do contexto, os interesses desses grupos podem fazer com que valor seja gerado para o próprio grupo, mesmo que isso signifique perda, prejuízo ou redução de valor para o cidadão. Comportamentos utilitários ou oportunistas podem ser, então, potencializados pela capacidade discricionária desses sujeitos e, nessa arena, nem sempre é tão simples afirmar que isso é ruim ou bom. Da mesma forma, quando esses atores reforçam a política, a discricionariedade não garante que o compromisso seja exclusivamente com o cidadão ou usuário, uma vez que outros interesses podem fazer com que essa estratégia seja escolhida.

Outro aspecto reforçado por Evans e Harris (2004) está relacionado ao desempenho e às funções das organizações que respondem pela implementação no nível de base, pressionadas pelos novos preceitos da gestão pública. Como esses espaços têm incorporado novas rotinas a fim de atender à cultura da gestão, da avaliação, do monitoramento, da transparência, da descentralização e do atingimento de metas, os agentes públicos, novamente, fazem escolhas que não necessariamente estão alinhadas com o princípio da geração de valor público.

As entrevistas realizadas com os assistentes sociais revelam esse componente quando deixam claro que, para atingir a meta de atendimento bimestral das famílias beneficiárias, será sacrificado o acompanhamento qualitativo das mesmas. Por causa do volume de trabalho, baixo número de funcionários e recursos disponíveis, escolhem, subjetivamente, as famílias que serão priorizadas. 
Os profissionais da escola, já envolvidos com as especificidades de seu trabalho, também traçam estratégias que refletem esses dilemas, conforme evidenciado em uma das entrevistas, quando o diretor da escola reclama que o volume de trabalho administrativo "rouba" tempo da gestão pedagógica da escola.

\section{Considerações finais}

Os profissionais que atuam nos espaços públicos aqui analisados podem ser considerados típicos burocratas no nível da rua, refletindo as descrições desenvolvidas por Lipsky (1980) e Winter (1993; 2003). Profissionais da educação e da assistência social têm suas próprias estratégias de ação, estão pouco sujeitos a controles gerenciais rígidos e exercem largamente sua intuição.

Em síntese, as decisões e comportamentos desses agentes não são exclusivamente "operacionais". A partir da contribuição de Converse (2004), os espaços em que os agentes de base atuam podem ser vistos como arenas onde os sistemas de crenças desses profissionais - e de outros que a ela se agregam temporariamente, como os profissionais da saúde, por exemplo - se encontram e definem estratégias de convivência e cooperação. Segundo esse autor, os indivíduos, através de um conjunto de valores, percepções, ideias e atitudes interconectadas, indicarão a previsibilidade de seu comportamento.

Em Belo Horizonte, o papel dos assistentes sociais e dos CRAS chama a atenção porque esses atores estão modificando a dinâmica e as relações no nível local, assumindo a função de articuladores locais. A presença dos CRAS tem ressignificado o papel da escola como única referência nesse nível para os cidadãos, retomando as contribuições de Algebaile (2009). Na medida em que servem como porta de entrada para a disponibilização das políticas sociais, modificam os padrões de interação entre os diversos agentes e equipamentos públicos que existem no território, potencializando estratégias de cooperação e relações do tipo ganha-ganha.

Os desafios que essa recomposição traz para a escola não são pequenos. Ao mesmo tempo em que a escola tem a chance de redefinir seu espaço e suas funções, desobrigando-se de desempenhar papéis que muitas vezes eram delegados a ela em função da ausência de outras instâncias de articulação na base, ela sofre pressões para aderir à rede de proteção social que vem sendo construída no município.

Do ponto de vista institucional, esse movimento é essencialmente tenso e marcado por idas e vindas, que podem ou não ser acentuadas pelos ciclos políticoeleitorais e pelas políticas públicas implementadas/interrompidas/redesenhadas 
nesse trajeto. De todo modo, pode-se afirmar que o Bolsa Família tem contribuído para produzir esse movimento positivo e necessário.

As contribuições de Lipsky (1980) e Moody \& Musheno (2003) sustentam a tese de que as instituições importam, mas não são capazes de, sozinhas, assegurar que o curso de ação das políticas públicas será seguido da forma como foi pensado ou desenhado. Em relação ao PBF e à condicionalidade educacional, isso é central para se compreender o impacto (positivo) causado pelos CRAS e pela atuação dos profissionais da assistência social. Mesmo com todas as dificuldades institucionais e operacionais identificadas, inerentes à constituição de redes de proteção social ou à definição de ações intersetoriais, os agentes que estão na base estão inclinados à cooperação e às trocas. É essa dinâmica que explica como as políticas são implementadas pelos agentes de base.

\section{Referências bibliográficas}

Algeballe, E. Escola pública e pobreza no Brasil: a ampliação para menos. Rio de Janeiro: Lamparina, 2009.

BALL, S. The micro politics of school. Oxford: Penguin Books, 1987.

Campelo, T.; Nerı, M. C. (org.) Programa Bolsa Família: uma década de inclusão e cidadania. Brasília: Ipea, 2013. 494 p.

Converse, Philip. The nature of belief systems in mass publics. In: Jost, John \& Sidanius, Jim (eds). Political psychology: key readings. New York: Psychology Press, 2004. p. 181-199.

CROzIer, Michel. O fenômeno burocrático: ensaio sobre as tendências burocráticas dos sistemas de organização modernos e suas relações na França, com o sistema social e cultural. Brasília, DF: Universidade de Brasília, 1981.

Derouet, J. O funcionamento dos estabelecimentos de ensino em França: um objecto científico em transformação. In: BARROSo, J. O estudo da escola. Porto: Porto Editora, 1995. Evangelista, O; Shiroma, E.S. Professor: protagonista e obstáculos da reforma. Educação e Pesquisa, vol 33, n. 3, p.531-541, set-dez. $2007 .$.

Franco. M. Quando nós somos o outro: questões teórico-metodológicas sobre os estudos comparados. Educação \& Sociedade, ano XXI, n. 72, Agosto/2000.

HaRRIS, J; eVAns T.; Street-Level Bureaucracy, Social Work and the (Exaggerated) Death of Discretion. British Journal of Social Work, n.34, p. 871-895, 2004.

HILL, Michael. The Policy process in the Modern State. Third Edition. Prentice Hall, 1997. LIPSKY, M. Street-level bureaucracy: dilemmas of the individual in public services. Nova York: Russell Sage Foundation, 1980.

LotTA, G.S; Agentes de implementação: mediação, dinâmicas e estruturas relacionais. Caderno de Gestão Pública e Cidadania, São Paulo, v.15, n.56, 2010. 
Marques E.; Moya, E. Trocas Sociais, apoios e mecanismos relacionais. In: Marques, Eduardo (org.) Redes sociais no Brasil - sociabilidade, organizações civis e políticas públicas. Belo Horizonte: Fino Traço, 2012. cap 4.

MARques, Eduardo (org.) Redes sociais no Brasil - sociabilidade, organizações civis e políticas públicas. Belo Horizonte: Fino Traço, 2012.

Musheno, M.; Moody, M. S. Cops, Teachers, Counselors- Stories from the front Lines of Public Service. The University of Michigan Press, 2003.

Nerı, M. Focalização, universalização e políticas sociais. Rio de Janeiro: Econômica, v.5, n.1, p.163-170, junho de 2003.

NóvoA, A. O processo histórico de profissionalização do professorado. Porto: Porto Editora, 1991.

Oliveira, B. A implementação dos programas Bolsa Família e Oportunidades sob a perspectiva da condicionalidade educacional: uma análise a partir dos agentes públicos de base. Belo Horizonte: FAE/UFMG, 2014 (tese de doutorado).

Oliveira, L.; Soares, Sergei. Bolsa Família e repetência: resultados a partir do Cadúnico, Projeto Frequência e Censo Escolar. In: Campelo, T.; NerI, M. C. (org.) Programa Bolsa Família: uma década de inclusão e cidadania. Brasília: Ipea, 2013. 494 p.

SelzNick, Philip. TVA and the grass roots: a study in the sociology of formal organization. New York: Harper \& Row, 1966.

Soares, S.; SÁtiro, N. O Programa Bolsa-Família: desenho institucional e possibilidades futuras. Brasília: Ipea, 2009 (texto para discussão).

WILSON, James Q. Bureaucracy: what government agencies do and why they do it. United States: Basic Books, 1989

WINTER, S. Integrating Implementation Research. In: Dennis J. Palumbo and Donald, 1993.

Winter, S. Political Control, Street-Level Bureaucrats and Information Asymmetry in Regulatory and Social Policies. Paper prepared for the Annual Research Meeting of the Association for Public Policy Analysis and Management held in Washington D.C, November 6-8, 2003.

Doutor em Educação pela Universidade Federal de Minas Gerais (UFMG) e Professor Adjunto da Universidade Federal de Ouro Preto (UFOP). Contato: breynner@cead.ufop.br 